\section{Viral distemper now found in porpoises}

SIR-Although thousands of seals (Phoca vitulina) have died in European seas since April 1988 from a morbillivirus infection, there have been no reports of morbillivirus infection in other marine mammals during the current epizootic. We now document distemper in two common porpoises (Phocoena phocoena) recently found dead on the coast of Northern Ireland.

Necropsy reveals severe pneumonia characterized by proliferation of type II pneumonocytes, syncytia formation, inflammatory cell infiltration and necrosis of bronchial and bronchiolar epithelium. Acidophilic intracytoplasmic inclusion bodies highly specific for morbillivirus infection are seen in bronchial and bronchiolar epithelium. There is widespread degeneration and necrosis of neurons, gliosis and perivascular cuffing in the brain consistent with viral aetiology. Many neurons contain inclusion bodies. Inclusions are also seen in transitional epithelium of the renal pelvis and urinary bladder.

We exanined paraffin sections of tissues from both porpoises for morbillivirus antigen by an immunoperoxidase technique. Measles antiserum from a patient with subacute sclerosing panencephalitis was used as the primary antibody. Tissues from a seal with distemper and a porpoise necropsied at our laboratory in 1987 were used as positive and negative controls respectively.

Morbillivirus antigen was detected in both animals. As shown in the figure, there is specific intracytoplasmic and intranuclear staining in neurons and astrocytes in the brain. Antigen is also seen in bronchial and bronchiolar epithelium and pneumonocytes in the lung and in transitional epithelium of the renal pelvis and urinary bladder. The microscopic changes in our porpoises are similar to those of canine distemper virus infection in other species including seals ${ }^{1.2}$. Demonstration of morbillivirus antigen in diseased tissue confirms such a virus as the primary cause of the lesions.

This is the first report of morbillivirus

infection in cetaceans. We do not know how the porpoises contracted the infection. The pattern of spread of the seal epizootic is temporally and geographically similar to the annual migration of porpoises from the Baltic to the North Sea and south to the English Channel ${ }^{3}$, so it is possible that porpoises acted as vectors in the southerly

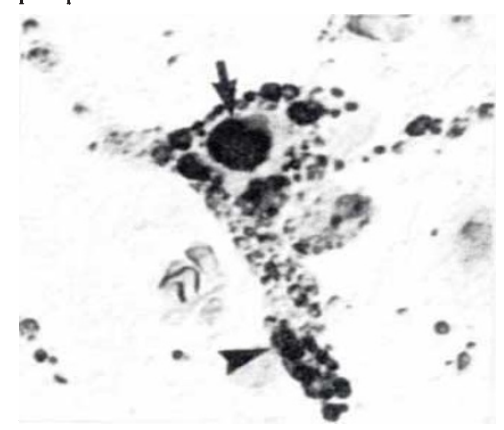

Immunoperoxidase staining of morbillivirus antigen in nucleus (arrow) and cytoplasm (arrowhead) of a neuron. $\times 650$.

spread of the seal epizootic. Porpoises are known to cross the Atlantic Ocean, so marine mammals along the American continent could be at risk.

Our findings may explain the declines in porpoise and dolphin populations in European waters in recent years. Retrospective serological examination of stored cetacean blood samples, and detailed post-mortem and serological examinations of cetaceans found ill or dead would help establish the timing and extent of morbillivirus infection in these species.

S. KENNEDY

J. A. SмYTH P. F. Cush

S. J. MCCullough G. M. Allan

Veterinary Research Laboratories, Stormont, Belfast BT4 3SD, UK

Department of Pathology, S. MCQuAID Queen's University, Belfast BT7 INN, UK

Kennedy, S. et al. Nature 335. 404 (1988)

2. Dungworth. D.L. in Pathology of Domestic Animals Vol. 2 (eds Jubb. J.V.F.. Kennedy, P.C. \& Palmer. N.) Ch. 6 (Academic. London. 1985).

3. Matthews. L.H. The Natural History of the Whale 131 (Weidenfeld and Nicolson. London. 1978)

\section{Did virus transfer from harp seals to common seals?}

SIR-A morbillivirus related to canine distemper virus (CDV) is apparently responsible for the recent epidemic deaths of common (or harbour) seals, Phoca vitulina L., in the North Sea and the Baltic'. Osterhaus et al. ${ }^{2}$, investigating the virus in seal populations, have reported finding no CDV-neutralizing antibodies in samples collected from eight different seal species before the present outbreak of the disease. These include four of the five phocine genera (Phoca, Pusa, Histrio- been endemic allowing acquired immunity to the virus to develop, to common seals, which had not been previously exposed to the virus. The disastrous results would be similar to what happened when the myxomatosis virus, endemic in American cottontail rabbits (Sylvilagus spp.) as a mild disease, was introduced into the European rabbit, Oryctolagus cuniculus (L.) in the $1950 \mathrm{~s}$, where it was highly lethal.

This hypothesis could be tested by attempting to infect harp seals with virus taken from diseased common seals, when it should produce only relatively mild symptoms. And CDV-neutralizing antibodies would be expected to be found in samples taken from harp seals within their normal range both now and, if any are available, from previous years.

Gonville and Caius College,

C. B. GoOdhart

Cambridge CB2 1TA, UK

1. Osterhaus. A.D.M.E. \& Vedder. E.J. Nature 335, 20 (1988)

Osterhaus. A.D.M.E. et al. Nature 335. 403 (1988)

\section{Is bacterial evolution random or selective?}

SIR-J. Cairns et al. (Nature 335, 142-145; 1988) raise the question of whether bacterial evolution always proceeds by a random process or if bacteria have the ability to sense specific needs and direct mutational events to satisfy those needs. The present generation of microbial geneticists, having been taught in their formative years that mutations are random events and that selections serve only to identify those rare individuals which contain the appropriate mutation, will take comfort in the reconfirmation of the Luria and Delbruck results by Cairns et al.. But the idea that bacteria can specifically sense metabolic needs during a selection and respond by directed mutagenesis will no doubt be met with much scepticism, for the questions raised involve an aspect of biology we know little about, that is, adaptation and macromolecular synthesis during starvation conditions. Although the actual experimental data presented are sketchy and the details of the experimental procedures are lacking, one is left with the feeling that the phenomenon reported by Cairns et al. is real and warrants further investigation.

I also have been investigating the events that lead to the appearance of mutant colonies on agar plates during a non-lethal selection. This selection demands that cells grow on a carbon source whose molecules are too large to easily cross the outer membrane. I obtained mutants which continued to appear for many days after plating. These mutants have mutations that predominantly alter one of the outer membrane porin proteins $(\mathrm{OmpF})$. 